\title{
REGÍMENES PATRIMONIALES Y REGISTROS DE LA PROPIEDAD DE LAS PAREJAS TRANSFRONTERIZAS ${ }^{1 *}$
}

\author{
LUCIA RUgGerI ${ }^{2 *}$ \\ Catedrática de Derecho civil en la Universidad de Camerino \\ E-mail: lucia.ruggeri@unicam.it \\ Manuela Giobbi \\ Profesora de Derecho civil en la Universidad de Camerino \\ E-mail: mangiobbi@gmail.com
}

\begin{abstract}
RESUMEN: Los Reglamentos gemelos sobre los regímenes patrimoniales y las consecuencias patrimoniales de las parejas transfronterizas excluyen de su ámbito de aplicación las cuestiones relativas a la inscripción de los bienes inmuebles y de la propiedad (artículo 1, apartado 2, de los Reglamentos gemelos). Existe una estrecha conexión entre el régimen patrimonial, la propiedad o la copropiedad de un bien, las normas de registro y la protección de terceros que, por ejemplo, tengan una reclamación contra uno de los miembros de la pareja. Los Reglamentos gemelos excluyeron expresamente de su ámbito de aplicación "cualquier inscripción en un registro de derechos sobre bienes muebles o inmuebles, incluidos los requisitos legales para llevarla a cabo, y los efectos de la inscripción o de la omisión de la inscripción de tales derechos en un registro" (letra $\mathrm{h}$ ) del apartado 2 del artículo 1). Pero esta exclusión realizada por los Reglamento gemelos no es concluyente. En concreto, no elimina la necesidad de estudiar la interferencia entre la ley aplicable y a verificar la repercusión en la posición del tercero que, por diversas razones, entró en contacto con uno o ambos miembros de la pareja.

Palabras clave: relaciones de propiedad, Lex registri, Registro, Reglamentos gemelos, parejas tranfronterizas.
\end{abstract}

ABSTRACT: The Twin Regulations on property regimes and the property consequences of cross-border couples exclude from their scope of application matters of real estate and property disclosure (Article 1(2) of the Twin Regulations). Therefore, a close connection exists between a property regime, ownership or joint ownership of a property, registration rules and the protection of third parties who, for example, have a claim against one of the couple. The Twin Regulations expressly excluded from their scope 'any recording in a

* Traducido por Fátima Pérez Ferrer, profesora titular de Derecho penal de la Universidad de Almería

2 * Lucia Ruggeri es autora de las secciones I., II., III. y IV.; Manuela Giobbi es autora de las secciones V., VI., VII., VIII. y IX. 
register of rights in immoveable or moveable property, including the legal requirements for such recording, and the effects of recording or failing to record such rights in a register' (Article 1(2)(h). But this exclusion made by the Twin Regulations is not conclusive. It specifically does not eliminate the need to study the interference between the law applicable to the property relationship and the lex registri, verifying the impact on the position of the third party who, for various reasons, came into contact with only one or both of the couple.

Keywords: property regimes, Lex registri, Twin Regulations, Cross-border couples.

SUMARIO: I. LOS REGISTROS DE LA PROPIEDAD EN EUROPA: UN MARCO NORMATIVO FRAGMENTADO. II. AUTONOMÍA DE LA VOLUNTAD Y PROTECCIÓN DE LOS TERCEROS: UNA COMBINACIÓN DIFÍCIL. III. EL ARDUO, PERO NECESARIO, DIÁLOGO ENTRE LEX CAUSAE Y LEX REGISTRI. IV. EL PRINCIPIO DE UNIDAD DE LA LEY APLICABLE Y LA PROTECCIÓN DEL TERCERO: EL PAPEL DEL ARTÍCULO 28 DE LOS REGLAMENTOS GEMELOS. V. LEY APLICABLE A LAS RELACIONES PATRIMONIALES Y LOS EFECTOS FRENTE A TERCEROS. VI. LA INSCRIPCIÓN DE LOS DERECHOS REALES Y EL ÁMBITO DE APLICACIÓN DE LOS REGLAMENTOS GEMELOS. VII. DECLARACIÓN DE BIENES Y EFECTOS RESPECTO A TERCEROS. VIII. ADAPTABILIDAD DE LOS DERECHOS REALES. IX. OBSERVACIONES FINALES.

\section{LOS REGISTROS DE LA PROPIEDAD EN EUROPA: UN MARCO NORMATIVO FRAGMENTADO}

Los Reglamentos gemelos, sobre los regímenes patrimoniales y las consecuencias patrimoniales de las parejas transfronterizas, excluyen de su ámbito de aplicación las cuestiones relativas a la inscripción de los bienes inmuebles y de la propiedad (artículo 1, apartado 2, de los Reglamentos gemelos). Esta exclusión no es nueva. El Reglamento sobre sucesiones también excluye de su ámbito de aplicación las cuestiones relativas a la inscripción en un registro de un derecho sobre bienes inmuebles o muebles (artículo 1, apartado 2, sub 1). Es la legislación del Estado miembro en el que se lleva el registro o donde se encuentra el bien inmueble la que determina las condiciones legales y los procedimientos de inscripción.

En este contexto, los registros de la propiedad constituyen un ámbito todavía muy caracterizado por la fragmentación legislativa ${ }^{3}$. Su armonización a nivel europeo es difícil debido al alto grado de diversidad de enfoques nacionales que caracteriza los derechos y obligaciones relativos a la propiedad inmobiliaria. Esto se observa en el ámbito de las garantías, así como en lo que respecta a la naturaleza y el contenido de las instituciones, como la multipropiedad, la tenencia, el trust, etc.

3 Significativamente, destaca que cada régimen patrimonial tiene una lógica interna con sus propias reglas en materia de escrituras de compra, disposición y divulgación. E. CALÒ, "Variazioni sulla professio iuris nei regimi patrimoniali delle famiglie" (2017) 6 Rivista del Notariato, 1093. 
Partiendo de esta situación, la exclusión que hace la normativa de la UE en materia de derecho de familia y sucesiones es una opción casi obligatoria cuyo objetivo es proporcionar seguridad jurídica, mientras que la remisión al derecho nacional evita de hecho la dificultad de determinar la legislación aplicable. La función de transparencia es tan importante que cualquier incertidumbre provocaría probablemente conflictos en ámbitos fundamentales como el conocimiento de actos o hechos de importancia relevante por parte de terceros. En algunos países, el vínculo de pareja determina la aparición de relaciones jurídicas peculiares de contenido patrimonial. En consecuencia, no sólo es necesario revelar el acto o hecho relevante que se pretende registrar, sino también la situación personal concreta de la persona, relacionada con dicho acto o hecho.

Esta fragmentación no facilita la vida de las parejas que viven en países distintos al de origen, o que están compuestas por personas de distintas nacionalidades. Cada Estado atribuye la llevanza de los registros a diferentes ministerios y organiza el registro de diversas maneras, centralizando, descentralizando, separando o agregando en un solo registro la información relativa al régimen económico matrimonial o de la pareja registrada y la relativa a las garantías inmobiliarias o de propiedad.

Por esta razón, el diálogo entre los Registros de la propiedad iniciado por el proyecto del Servicio Europeo de Información Territorial (EULIS) ${ }^{4}$ y continuado con el proyecto de Interconexiones de los Registros de la Propiedad (LRI) ${ }^{5}$ debe considerarse una herramienta complementaria a las políticas europeas establecidas en los Reglamentos gemelos. La libertad de circulación prevista en el artículo 21 del TFUE también puede hacerse efectiva y fomentarse a través de una organización diferente de los registros de la propiedad destinada a hacerlos fácilmente accesibles e inteligibles.

La accesibilidad a los diferentes Registros de la propiedad sería más fácil para los ciudadanos y las empresas, siempre que la interoperabilidad tecnológica vaya acompañada de una cuidadosa aclaración de la terminología jurídica para comprender mejor las similitudes o diferencias que las instituciones atribuyen al término "propiedad". En los sistemas en los sistemas del Common Law, esta palabra tiene un significado amplio que incluye no sólo el suelo, sino también todos los bienes inmuebles y todo tipo de derechos ejercidos sobre estos bienes ${ }^{6}$. Un término tan amplio, que se encuentra en el ordenamiento jurídico italiano (artículo 813 del Código Civil italiano) ${ }^{7}$, y puede dificultar la interoperabilidad. La opción legislativa europea se justifica también por el hecho de que los Estados han desarrollado a lo largo del tiempo medidas que identifican regímenes normativos específicos para determinados bienes o derechos ${ }^{8}$. Por ejemplo, basta con considerar el

4 El proyecto (iniciado en 2006) ha permitido la integración de los registros de los siguientes países: Irlanda (Property Registration Authority), Lituania (Valstybės įmonė Registrų centras - State Enterprise Centre of Registers), Países Bajos (Kadaster), Austria (Bundesministerium für Justiz) y España (Colegio de Registradores de la Propiedad, Mercantiles y de Bienes Muebles de España).

5 El objetivo de este proyecto es crear un punto de acceso único a través de un portal de justicia electrónica, cuya descripción puede encontrarse en. https://dg-justice-portal-demo.eurodyn.com/ejusticeportal/content land registers_interconnection_lri-36276-en.do

6 V.I. FERRARI, Land Law nell'Era Digitale, Cedam, Padua 2013, p. 4.

7 El artículo 813 del Código Civil italiano dice: "Salvo que la ley disponga otra cosa, las disposiciones relativas a los bienes inmuebles se aplican también a los derechos reales sobre los mismos y a las acciones conexas; las disposiciones relativas a los bienes muebles se aplican a todos los demás derechos".

8 S. GARDNER y E. MACKENZIE, An Introduction to Land Law, Hart Publishing, Oxford, 4 a ed. 2015, Hart Publishing, Oxford, p. 7. 
concepto de propiedad y las dificultades para distinguir entre distintos modelos como el arrendamiento a largo plazo ${ }^{9}$. También hay sistemas como el alemán o el anglosajón ${ }^{10}$ en los que la inscripción de la venta de bienes inmuebles tiene efecto constitutivo de ley ${ }^{11}$, a diferencia de los sistemas de base personal, como el italiano, en los que la transcripción tiene principalmente una función declarativa ${ }^{12}$.

La armonización llevada a cabo por la UE a través de instrumentos normativos que implican sólo a algunos Estados miembros (como los Reglamentos gemelos) agrava el problema. En efecto, el conjunto de terceros Estados en materia de registro de los regímenes patrimoniales familiares está compuesto no sólo por los terceros países tradicionales, sino también por todos aquellos Estados miembros de la UE que no se han adherido al procedimiento de cooperación reforzada que condujo a la adopción del Reglamento sobre los regímenes económicos matrimoniales y del Reglamento sobre los efectos patrimoniales de las uniones registradas. La elección de la pareja de formalizar una comunión de vida en forma de matrimonio o de unión registrada a través de un procedimiento de registro que no ha sido armonizado se combina con la regulación no armonizada del registro de las consecuencias patrimoniales derivadas de los diferentes modelos de familia. Desde esta perspectiva, la exclusión de la cuestión de la publicidad y registro de la legislación europea es sólo una solución temporal a un problema que sigue existiendo: ninguna armonización del ámbito de las consecuencias patrimoniales de la familia puede funcionar bien si no es posible lograr también la armonización de las normas relativas al registro de los modelos de familia y de las consecuencias patrimoniales de los modelos elegidos. Incluso cuando el legislador ha preferido no introducir regímenes patrimoniales específicos derivados del matrimonio, la disciplina patrimonial puede verse influida por la presencia de un matrimonio. Se puede hacer referencia a la jurisprudencia inglesa relativa a la cesión de la vivienda familiar. En un país que atribuye un valor constitutivo ejemplar a los registros de la propiedad, esta posición se mantuvo en el caso Grant v Edwards ${ }^{13}$. En este último, una mujer casada que no era propietaria de la casa obtuvo el reconocimiento de la propiedad común del inmueble. Ello se hizo sobre la base de una valoración del comportamiento de las partes y de las circunstancias concretas de las que se desprendía que era contrario a la buena fe asignar el título formal de la propiedad únicamente al marido.

Las interferencias entre las situaciones familiares, las estructuras de propiedad y los diferentes sistemas de registro de los títulos de propiedad ${ }^{14}$ son tales que es necesario

9 V.M.P. THOMPSON y M. GEORGE, Modern Land Law, Oxford University Press, Oxford 2017, p. 245.

10 M.D. PANFORTI, “Torrens title” Digesto delle Discipline Privatistiche, Utet, Torino 2000, Agg. I, p. 715. Sobre el sistema original aleman Torrens V, entre otros, A. ESPOSITO, 'Ulrich Hubbe's Role in the Creation of the Torrens System of Land Registration in South Australia' (2003) 24 Adelaide Law Review 2, pp. 263-304, HeinOnline.

11 Por ejemplo, en Inglaterra y Gales, la publicidad ha adquirido un valor constitutivo tras la Ley de Registro de la Propiedad de 2002. V.I. FERRARI, Land Law nell'Era Digitale, Cedam, Padova 2013, pp. 185-186.

12 En algunas regiones italianas (Trentino Alto-Adige y Friuli Venezia Giulia) existe un sistema de publicidad inmobiliaria de origen alemán llamado "intavolazione". Este tipo de transcripción tiene efectos constitutivos. Véase F. PADOVINI, voce "trascrizione”, en Novissimo Digesto Italiano, app. VII, Torino, 1987, p. 800 ss.

13 Grant v Edwards [1986] 3 WLR 114 Tribunal de Apelación.

14 La variada taxonomía de las parejas, que ya no puede reducirse al esquema del matrimonio heterosexual, ha llevado a referirse a los regímenes patrimoniales "derivados de las opciones sexuales". Hablan de "derecho de propiedad sexual” G.L. GRETTON y A.J.M. STEVENS, Property, Trusts and Succession, Bloomsbury, Londres 2017, p. 112. Más en general sobre este tema véase W. PINTENS, "Matrimonial Property Law in Europe", en K. BOELE-WOELKI, J. MILES y J. M. SCHERPE (coords), The Future of Family Property in Europe, Intersentia, Antwerpen 2011, pp. 19-46; K. BOELE-WOELKI, F. FERRAND, C. GONZÁLEZ-BEILFUSS, M. JÄNTERÄ- 
armonizar los sistemas de registro entre los distintos Estados. Este proceso, prefigurado por la UE desde la adopción del Libro Verde sobre el crédito hipotecario ${ }^{15}$, aún no se ha producido. El debate sobre esta cuestión con referencia al marco europeo introducido por los Reglamentos gemelos sólo puede tomar nota de ello.

La legislación actual relativa a los regímenes económicos matrimoniales y efectos patrimoniales de las uniones registradas tiene sus efectos más allá de la propia pareja. Puede afectar a todo el mundo siempre que se trate de derechos reales, en tanto que éstos tienen efectos erga omnes en la tradición legislativa de muchos Estados. Por lo tanto, existe una estrecha conexión entre el régimen patrimonial, la propiedad o la copropiedad de un bien, las normas de registro y la protección de terceros que, por ejemplo, tengan una reclamación contra uno de los miembros de la pareja. Los Reglamentos gemelos excluyeron expresamente de su ámbito de aplicación "cualquier inscripción en un registro de derechos sobre bienes muebles o inmuebles, incluidos los requisitos legales para llevarla a cabo, y los efectos de la inscripción o de la omisión de la inscripción de tales derechos en un registro" (letra h) del apartado 2 del artículo 1). Pero esta exclusión realizada por los Reglamento gemelos no es concluyente. En concreto, no elimina la necesidad de estudiar la interferencia entre la ley aplicable y a verificar la repercusión en la posición del tercero que, por diversas razones, entró en contacto con uno o ambos miembros de la pareja.

\section{AUTONOMÍA DE LA VOLUNTAD Y PROTECCIÓN DE LOS TERCEROS: UNA COMBINACIÓN DIFÍCIL}

La ley aplicable identificada sobre la base de los Reglamentos gemelos determina los efectos del régimen patrimonial entre los cónyuges o los miembros de la pareja registrada y las relaciones jurídicas entre un cónyuge o un miembro de la pareja y los terceros ${ }^{16}$. La ley identificada por los cónyuges antes o durante el matrimonio o la unión registrada constituye la lex causae. No sólo rige las relaciones patrimoniales de la pareja, sino que, como se destaca en el considerando 18 del Reglamento de régimen económico matrimonial, incluye también las relaciones entre un cónyuge individual y terceros. Este tercero puede ser acreedor de uno o de ambos cónyuges o miembros de la pareja, y la relación puede derivar de un contrato, de un hecho ilícito o de cualquier otro acto o hecho que pueda dar lugar a una relación obligatoria.

La ley aplicable a los regímenes matrimoniales o a las consecuencias patrimoniales de una unión registrada es la expresión de la libertad de negociación de la pareja, que, por disposición expresa del artículo 22 del Reglamento, también podría modificarse con efecto retroactivo. Se salvaguarda la posición del tercero impidiendo que el ius variandi ejercido por la pareja afecte negativamente al tercero. En este caso seguirá surtiendo efecto la ley inicialmente aplicada al régimen patrimonial ${ }^{17}$.

JAREBORG, N. LOWE, D. MARTINY y W. PINTENS, Principles of European Family Law Regarding Property Relations Between Spouses, Intersentia, Antwerpen 2013, pp. 1-420.

15 COM (2005) 0327 final.

16 Se observa un error tipográfico en el artículo 27, letra f, del Reglamento sobre las consecuencias patrimoniales de las uniones registradas (traducción al italiano), donde en lugar de pareja se dice "cónyuge" ("coniuge").

17 Existe un amplio debate sobre la posible retroactividad del ius variandi. V.L. RADEMACHER, "Changing the Past: Retroactive Choice of Law and the Protection of Third Parties in the European Regulations on Patrimonial 
Existen muchos escenarios posibles a la hora de celebrar un acuerdo sobre la elección de la ley. Las parejas pueden determinar la ley aplicable antes de formalizar su unión, o pueden esperar a la celebración del matrimonio o de la unión registrada, pueden quedarse con la ley elegida en primer lugar, o pueden cambiarla posteriormente, incluso con carácter retroactivo, o bien hacer una elección de la ley que surta efecto a partir de una fecha determinada. La elección de la ley aplicable, así concebida, responde a las necesidades de la pareja que, basándose en la situación concreta, puede identificar qué ley, de qué Estado puede regir mejor la relación. Sin embargo, esto es menos satisfactorio para los terceros que entran en contacto con la pareja.

Los Reglamentos gemelos se adoptaron sobre la base del artículo 81, apartado 3, del TFUE como instrumentos de Derecho de familia con implicaciones transnacionales. Sin embargo, es cierto que siempre que un miembro individual de una pareja o ambos celebran contratos o asumen obligaciones, la actividad jurídica interactúa con el Derecho de familia. Aunque la exclusión de la publicidad, por una parte, respeta las tradiciones de cada Estado y constituye el leitmotiv de la legislación europea en materia de familia y sucesiones, por otra, impide un nivel adecuado de protección a terceros.

Los Reglamentos gemelos han intervenido en un ámbito que ni siquiera los convenios internacionales han podido regular. En $1905^{18}$ se elaboró un convenio sobre los efectos del matrimonio, que fue anulado por las dos guerras mundiales. En 1978, otro convenio ${ }^{19}$ reguló específicamente los regímenes patrimoniales entre los cónyuges; sin embargo, tampoco tuvo éxito, ya que sólo fue ratificado por Francia, Luxemburgo y los Países Bajos. Desde este punto de vista, la adopción de los Reglamentos gemelos supone un gran éxito en el camino emprendido por la UE para simplificar la vida de las parejas transfronterizas.

El ejercicio de la llamada autonomía de la voluntad ${ }^{20}$, base de cualquier norma que introduzca la libertad de elección de la ley aplicable, supone, en materia familiar, sacrificar las necesidades de terceros. Las relaciones familiares no son exclusivamente personales, sino que inevitablemente incluyen también un enfoque patrimonial. El hogar es un lugar en el que se ejerce el derecho a la vida privada y familiar; pero, al mismo tiempo, constituye un bien regulado por las normas del derecho inmobiliario. Para llevar a cabo su vida, la pareja establece necesariamente diferentes relaciones contractuales. El deseo de pasar juntos el tiempo libre es probable que incluya la celebración de contratos de arrendamiento de viviendas vacacionales. Por este motivo, en algunos países, el matrimonio o la celebración de una unión registrada también tiene consecuencias en el régimen patrimonial de los miembros de la pareja. Estas consecuencias repercuten inevitablemente en las relaciones con terceros que establecen vínculos obligacionales con los miembros

Consequences of Marriages and Registered Partnerships" (2018) 10 Cuadernos de Derecho Transnacional 1, 10.

18 Se trata del Convenio de La Haya de 17 de julio de 1905 sobre los bienes matrimoniales. El texto puede consultarse. https:/www.hcch.net/en/instruments/the-old-conventions/1905-effects-of-marriage-convention.

19 Se refiere al Convenio de La Haya de 14 de marzo de 1978 sobre la ley aplicable a los regímenes matrimoniales.

20 La adopción del criterio de la autonomía de la voluntad para identificar la ley aplicable en contextos caracterizados por la internacionalidad se remonta a un célebre caso francés (véase Cass. civ., 5 de diciembre de 1905, American Trading Company v Quebec Steamship Company Limited), pero también constituye una tradición que se remonta a la cultura inglesa (véase Girnar v Meyer (1796), 2 Hy. Bl. 603). Sobre este tema, véase M. GIULIANO y P. LAGARDE, "Relazione sulla Convenzione relativa alla legge applicabile alle obbligazioni contrattuali", Comunicazione al Consiglio, en OJ 31 de octubre de 1980, C 282, p. 16. 
de la pareja. Por lo tanto, los efectos de la autonomía de la pareja se desenvolverán más allá de la propia pareja, lo que implica una inversión del principio tradicional según el cual un acuerdo sólo tiene efecto entre las partes que lo estipulan. La elección de una comunión de vida sellada por un matrimonio formal o una unión registrada, en el caso de las parejas transfronterizas, determina la posibilidad de elegir la ley aplicable a la relación con consecuencias inevitables sobre terceros. El artículo 27, letra f, del Reglamento reafirma, pues, la eficacia de un principio consolidado en el Derecho internacional privado. Sin embargo, se caracteriza por una mayor dificultad de aplicación. En efecto, el tercero se encuentra con la carga de conocer la ley elegida por las partes o la elección que afecta temporalmente a las relaciones de pareja cuando ésta ha ejercido el ius variandi que le otorgan los apartados 2 y 3 del artículo 22 de ambos Reglamentos.

El ámbito de aplicación de la ley elegida es muy amplio, ya que se refiere no sólo a las materias enumeradas por el artículo 27 de los Reglamentos, sino también a los aspectos adicionales que las partes deseen asignar a la ley elegida o que entren en el ámbito de aplicación de la ley como efecto determinado por la ley nacional específicamente aplicable ${ }^{21}$. El impacto del artículo 27 sobre los terceros es aún más interesante si tenemos en cuenta que esta disposición no figuraba en la propuesta original del Reglamento ${ }^{22}$. Cada Estado tiene su propio enfoque de las consecuencias patrimoniales del matrimonio o de las uniones registradas. Como consecuencia de ello, muchas de las cuestiones a las que se refiere el artículo 27 de ambos reglamentos se habrían regido, sin esta intervención normativa específica, por la lex fori y no por la ley elegida por las partes. Sin embargo, una disposición como ésta, permite la posibilidad de ampliar las materias que se someten a la ley elegida, lo que reduce el impacto de la posible aplicación de la lex fori. Las consecuencias de la lex causae en ámbitos muy relevantes para quienes entran en contacto con la pareja son muy problemáticas. Por un lado, esto excluye la posibilidad de que el Reglamento regule aspectos como la naturaleza de los derechos reales o cuestiones relativas al registro de títulos sobre bienes muebles o inmuebles, mientras que, por otro lado, el instrumento de elección de la ley aplicable permite resolver muchas cuestiones por la lex causae con la consiguiente exclusión del efecto de la lex fori que hubiera estado operando por defecto en materias excluidas del ámbito de aplicación de los Reglamentos gemelos.

Para las cuestiones relativas a los derechos reales, la lex fori estará en vigor. El juez también podrá identificar un derecho real correspondiente en su propio ordenamiento jurídico que pueda producir los efectos que las partes hubieran querido producir utilizando un derecho real de otro ordenamiento jurídico, pero que no existía en el ordenamiento jurídico del juez ${ }^{23}$.

Cualquier cuestión relativa a la inscripción en un registro pertenece a la lex registri, que no coincide necesariamente con la lex fori: cuando se trata de un bien inmueble, las cuestiones relativas a la inscripción de la propiedad entran en el ámbito de aplicación del lugar donde se encuentra el bien inmueble (lex rei sitae). El sistema registral se

21 J.M. CARRUTHERS, “Article 27”, en I. VIARENGO y P. FRANZINA (coords), The EU Regulations on the Property Regimes of International Couples. A Commentary, Edward Elgar Publishing 2020, p. 262.

$22 \operatorname{COM}$ (2011) 126 final. La introducción de precisiones sobre el ámbito de aplicación de la autonomía de la voluntad es objeto de debate permanente. Véase, entre otros, O. LANDO, "Contracts", en K. LIPSTEIN (coord), Private International Law, en International Encyclopedia of Comparative Law, vol. III, Brill, Leiden 1977, pp. 106-125.

23 Véase P. BRUNO, I regolamenti europei sui regimi patrimoniali dei coniugi e delle unioni registrate, Giuffrè, Milán 2019, pp. 62-63. 
consideró excluido de la armonización con el objetivo de salvaguardar la competencia exclusiva de los Estados para organizar mejor los requisitos de inscripción de un bien en un registro específico. La lex registri, que en el caso de los bienes inmuebles coincide con la lex rei sitae, determina las condiciones de inscripción, pero también permite identificar a las autoridades encargadas de verificar los documentos necesarios para la inscripción.

\section{EL ARDUO, PERO NECESARIO, DIÁLOGO ENTRE LEX CAUSAE Y LEX REGISTRI}

No es fácil desenredar este complejo marco normativo. Por un lado, hay que entender hasta qué punto la lex causae puede afectar a ámbitos concretos de la lex registri y, por otro, hay que comprobar cómo se modula el conocimiento de los terceros. Esto último es necesario para la exigibilidad de los efectos de los actos realizados por la pareja en relación con los bienes muebles e inmuebles que deben ser objeto de registro.

La lex causae permite identificar la naturaleza del bien, que en algunos países puede ser calificado legalmente como un bien personal o un bien común. Esta circunstancia repercute en un tercero acreedor que podrá contar con garantías patrimoniales cuyo contenido y condiciones serán establecidas por la lex causae. El marco normativo europeo en materia de regímenes patrimoniales familiares obliga a analizar el nivel de protección que se otorga a los terceros que entran en contacto con la pareja. La exclusión de la materia de los registros de la propiedad del ámbito de aplicación de la normativa no excluye esta materia de un análisis sobre la situación concreta del tercero. Éste acaba siendo influenciado por la lex causae en condiciones relevantes, como el conocimiento que el tercero pueda tener sobre el régimen patrimonial familiar.

Los sistemas de publicidad de los regímenes patrimoniales son diferentes en cada estado o están completamente ausentes en algunos de ellos. Por ejemplo, en Austria ${ }^{24}$, Croa$\mathrm{cia}^{25}$, Irlanda, Eslovaquia o Luxemburgo, no se prevé ninguna forma de divulgación de los regímenes de propiedad familiar. Chipre también es diferente, ya que ha introducido el principio de "independencia patrimonial" tanto para los matrimonios ${ }^{26}$ como para las uniones civile $^{27}$ : el matrimonio o la unión civil no afectan a la independencia patrimonial de los cónyuges o de las parejas ${ }^{28}$. Polonia también carece de registros específicos en los que es posible obtener información sobre los regímenes patrimoniales a partir del Registro Central de Actividades Empresariales ${ }^{29}$, al igual que Suecia, donde el registro de los acuerdos de los cónyuges y las parejas de hecho se gestiona exclusivamente a efectos fiscales ${ }^{30}$.

En algunos Estados, como Italia, la publicidad tiene lugar a través del registro civil. Cuando la lex causae es la ley italiana, un tercero interesado puede identificar si está

24 Véase T. PERTOT, "Austria”, en L. RUGGERI, I. KUNDA y S. WINKLER (coords), Family Property and Succession in EU Member States. National Reports on the Collected Data, Rijeka Faculty of Law, Rijeka 2019, p. 9.

25 Véase M. BUKOVAC PUVAČA, “Croacia”, en L. RUGGERI, I. KUNDA y S. WINKLER (coords), “ibid”, p. 77.

26 See L. 232/1991, Sezione 13.

27 Véase L. 184(I)/2015, artículo 33.

28 Véase A. Plevri, "Cyprus", en L. RUGGERI, I. KUNDA y S. WINKLER (coords), "ibid" Family Property and Succession in EU Member States. National Reports on the Collected Data, p. 102.

29 Véase M. WĄSIC, "Polonia”, en L. RUGGERI, I. KUNDA y S. WINKLER (coords), "ibid”, p. 513.

30 Véase S. THORSLUND, “Suecia”, L. RUGGERI, I. KUNDA y S. WINKLER (coords), “ibid”, p. 663. 
en vigor el régimen especial de comunión legal o si existen acuerdos matrimoniales, o, de nuevo, un fondo patrimonial ${ }^{31}$. La naturaleza del bien y su régimen están regulados por la lex causae y, sobre esta base, un tercero podrá establecer qué derechos y facultades puede ejercer, o no, sobre un determinado bien.

Sin embargo, cuando un Estado establece formas de publicidad de los regímenes económicos, es necesario verificar para qué se proporciona dicha divulgación. En Italia, el Registro civil permite dos formas diferentes de divulgación. Por lo que respecta al estado civil (por ejemplo, actas de matrimonio, divorcio finalizado), el registro civil prevé la divulgación en forma de notificación, es decir, constituye una carga cuyo incumplimiento puede dar lugar a sanciones, pero no produce la nulidad. En caso de falta de inscripción, la carga de aportar la prueba de que el tercero tenía conocimiento de la situación de la que no había sido notificado recae en uno de los miembros de la pareja en cuestión. Si, por el contrario, la inscripción ha tenido lugar, el tercero no puede invocar el desconocimiento de esa situación concreta.

La inscripción de los acuerdos matrimoniales en el registro civil es, por el contrario, una revelación con efectos únicamente declarativos, cuya omisión hace que el acto sea imposible de invocar frente a terceros. Precisamente en lo que respecta a los regímenes patrimoniales o a las consecuencias patrimoniales de las uniones registradas, muchos Estados optan por una publicidad con efectos únicamente declarativos. Además de Italia, también Bélgica ${ }^{32}$, Finlandia, Portugal y España ${ }^{33}$ subordinan expresamente la posibilidad de invocar los efectos del matrimonio y/o la pareja de hecho frente a terceros a la inscripción de los acuerdos del matrimonio o de los distintos tipos de pareja en los registros civiles. Esto permite la posibilidad de que los efectos del matrimonio y/o las parejas de hecho puedan invocarse contra terceros ${ }^{34}$. En la legislación checa, la posición del tercero es objeto de una protección específica, ya que el acuerdo matrimonial no puede vulnerar los derechos del tercero, a menos que éste haya dado su consentimiento en el acuerdo ${ }^{35}$.

En Dinamarca, el régimen de separación elegido por la pareja debe ser divulgado mediante su publicación en el Boletín Oficial de Dinamarca (Statstidende) ${ }^{36}$ para que pueda ser invocado frente a terceros acreedores.

En Estonia y Rumanía, existen registros específicos dedicados a los regímenes matrimoniales, cuya gestión está asignada al Colegio de Notarios. Su objetivo es permitir que se invoque la existencia del régimen patrimonial frente a terceros, lo que proporciona un mayor nivel de protección de los intereses de los terceros y de seguridad jurídica ${ }^{37}$.

31 En Italia, la divulgación no es obligatoria, pero sólo si el acto ha sido transcrito puede oponerse a un tercero.

32 La lex causae puede, en virtud del principio de universalidad, ser también la de un Estado que no se ha adherido al procedimiento reforzado, lo que hace pertinente una investigación que incluye también a un Estado como Bulgaria.

33 En España, la inscripción de los acuerdos matrimoniales se produce en el Registro Civil. La regulación de los sistemas de publicidad de las parejas de hecho registradas, en cambio, no tiene carácter nacional y es expresión de la potestad normativa de las autoridades locales. Véase A.M. PÉREZ VALLEJO, "España”, en L. RUGGERI, I. KUNDA y S. WINKLER ( coords), “ibid”, p. 624.

34 Véase el artículo 1395 § 2 del Código Civil.

35 Based on Article 719 of the Civil Code, no legal effect can be produced by an agreement that has not involved the third party for the profiles of his or her concern.

36 Véase L. NIELSEN, Study on Matrimonial Property Regimes and the Property of Unmarried Couples in Private International Law and Internal Law, Europäische Kommission / Generaldirektion Justiz und Inneres, Bruselas 2003, pp. 1-78.

37 Véase S. LIIN, "Estonia”, en L. RUGGERI, I. KUNDA y S. WINKLER (coords), “ibid”, p. 193. Por la Rumanía contra G. RUSSO, “Rumanía”, en L. RUGGERI, I. KUNDA y S. WINKLER ( coords), “ibid”, p. 556. 
En Francia, aunque no existe un registro específico de regímenes patrimoniales, los terceros acreedores obtienen información de los cambios que se han producido en el régimen patrimonial de una pareja mediante un anuncio publicado en revistas especializadas. El llamado Pacto Civil de Solidaridad (PACS) se inscribe en el Registro Civil con el fin de dar a conocer su existencia a los terceros. No obstante, la ejecutabilidad del régimen de propiedad está sujeta a la transcripción de las escrituras de compra en los registros públicos de la propiedad ${ }^{38}$.

La inscripción del régimen económico elegido por la pareja, aunque no es necesaria para que la escritura sea válida, es una condición para que pueda ser invocada frente a terceros en el derecho alemán. La formación del registro en el Amtsgericht permite el conocimiento que hace de la situación patrimonial de la pareja aplicada contra el tercero ${ }^{39}$. Además, se prevé la publicación del registro en revistas especializadas en avisos legales.

En Grecia, un registro previsto en el Tribunal de Primera Instancia situado en Atenas recoge todos los acuerdos relativos a los regímenes patrimoniales de las parejas. Hungría dispone de un registro nacional específico de los acuerdos relativos a las relaciones patrimoniales de las parejas unidas en matrimonio o en pareja registrada. El registro, por tanto, certifica la existencia de los acuerdos y permite su aplicación frente a terceros. Lituania, Países Bajos y Eslovenia ${ }^{40}$ también llevan un registro específico de acuerdos matrimoniales: la falta de inscripción de los acuerdos en el registro hace imposible que se apliquen contra terceros, a menos que éstos tengan conocimiento de los mismos ${ }^{41}$.

Por el contrario, Malta no tiene un registro específico dedicado a los acuerdos matrimoniales; sin embargo, estos acuerdos deben inscribirse en el Registro Público que se lleva en el Ministerio de Justicia. Esta forma de registro cumple la función de notificación para los terceros, a los que, por tanto, se presume que tienen conocimiento jurídico de este hecho ${ }^{42}$.

Como puede concluirse, el diálogo innato entre la lex causae y la lex registri subraya la necesidad de evaluar caso por caso la posición del tercero: la relación entre el tercero y la pareja se rige, de hecho, tendencialmente por la lex causae, pero el sistema de notificación sigue anclado en la no siempre coincidente lex registri. En consecuencia, la autonomía de la voluntad de la pareja termina por sumarse a las cargas y obligaciones del tercero respecto de las normas específicamente aplicables a su relación.

\section{EL PRINCIPIO DE UNIDAD DE LA LEY APLICABLE Y LA PROTECCIÓN DEL TERCERO: EL PAPEL DEL ARTÍCULO 28 DE LOS REGLAMENTOS GEMELOS}

Del complejo marco normativo se desprende que la lex causae elegida por los cónyuges o socios rige todas las relaciones patrimoniales, incluidas las relativas a los bienes

38 Véase http://www.coupleseurope.eu/en/france/topics.

39 Véase T. Pertot, “Alemania”, en L. RUGGERI, I. KUNDA y S. WINKLER (coords), “ibid”, p. 268.

40 Véase F. DOUGAN, “Slovenia”, en L. RUGGERI, I. KUNDA y S. WINKLER (coords), “ibid”, p. 595.

41 Véase A. LIMANTE, "Lituania”, en L. RUGGERI, I. KUNDA y S. WINKLER ( coords), "ibid”, p. 416. Per l'Olanda v. F.W.JM SCHOLS y T.F.H. REIJNEN, "Países Bajos”, en L. RUGGERI, I. KUNDA y S. WINKLER (coords), "ibid", p. 493.

42 Véase M.V. MACCARI, "Malta”, en L. RUGGERI, I. KUNDA y S. WINKLER (coords), “ibid”, p. 468. 
inmuebles. El derecho inmobiliario no prevé ninguna excepción al principio de unidad introducido por el artículo 21 de los Reglamentos gemelos. Por tanto, este último se aplica a todas las relaciones patrimoniales familiares con elementos internacionales. La aplicación indiferenciada de la ley aplicable limita la autonomía negociadora de la pareja que no puede identificar una ley diferente para los bienes que se encuentran en países distintos de aquel cuya ley rige todas sus relaciones patrimoniales. Sin embargo, la técnica del dépeçage ${ }^{43}$ constituye una importante herramienta de gestión capaz de adaptar la elección de la ley aplicable a las necesidades y peculiaridades de un caso concreto. Combinando la adhesión al principio de unidad con la aplicación de la lex registri, resulta que es imposible perfilar una marco común y general de los distintos regímenes de publicidad de los bienes pertenecientes a las parejas unidas en matrimonio o en unión civil.

La primera dificultad es la inexistencia de una categoría única de terceros: sólo pueden identificarse remitiéndose a la lex causae que no coincide necesariamente con la lex registri como ley aplicable a los bienes. En general, se puede suponer que un tercero es un acreedor cuya posición se deriva de una obligación que no es necesariamente sólo contractual, o una persona con otros intereses protegidos hacia la pareja. Por lo tanto, dicho tercero puede hacer las respectivas reclamaciones patrimoniales.

La identificación del tercero y sus facultades en relación con los bienes de la pareja se desprende del artículo 28 del Reglamento de Gemelos, que prevé distintos supuestos con diferentes soluciones normativas.

Sólo si el tercero tiene un conocimiento efectivo de la ley aplicable al régimen patrimonial esta ley es invocable contra el tercero. La posibilidad de invocar esta ley determina que, sea cual sea la ubicación geográfica del inmueble, la ley aplicable a la relación entre la pareja y el tercero será la elegida por la pareja o la identificada mediante el artículo 26 de cualquiera de los Reglamentos gemelos. Como puede comprenderse, las condiciones subjetivas, como la residencia habitual o la ciudadanía común, devuelven en última instancia la relación entre el tercero y la pareja a un ámbito normativo que puede ser muy diferente del de la lex registri. En este sentido, el legislador europeo logra un buen equilibrio entre el automatismo legislativo y la protección de los terceros cuando en el artículo 26(3) del Reglamento, el penúltimo párrafo establece la división entre la lex causae y la ley aplicable a la relación entre el tercero y la pareja. En efecto, si uno de los miembros de la pareja, sobre la base del apartado 3 del artículo 26, ha solicitado a la autoridad judicial que decida sobre la base de una ley distinta de la prevista en el apartado 1 del artículo 26, la ley así identificada no puede regular las relaciones con el tercero, sino que puede ser eficaz exclusivamente para regular las relaciones patrimoniales de la pareja. En tal caso, se aplica la ley del Estado en el que los cónyuges o los miembros de la pareja han tenido una residencia habitual común durante un período significativo y más largo que el período de su vida transcurrido en la primera residencia habitual común.

43 La técnica del "dépeçage" es un concepto en el ámbito de los conflictos de normas por el que diferentes cuestiones dentro de un mismo caso se rigen por las leyes de diferentes. See 8 W. L M REESE, Dépeçage: A Common Phenomenon in Choice-of-law, (1973) 73 Colum L Rev at 58; C. G. STEVENSON, Dépeçage: Embracing Complexity to Solve Choice-of-Law Issues (2003-2004), 37 Ind L Rev 303 at 309. Un ejemplo de "dépeçage" puede encontrarse en el Convenio de Roma sobre la Ley aplicable a las obligaciones contractuales, art. 3(1): “

elección deberá manifestarse expresamente o resultar de manera inequívoca de los términos del contrato o de las circunstancias del caso. Por esta elección, las partes podrán designar la ley aplicable a la totalidad o solamente a una parte del contrato". 
La razón guía la identificación de la ley aplicable a las relaciones con terceros. La lex causae vincula al tercero incluso con el mero conocimiento de la ley aplicable, ya que no se requiere un conocimiento real, sino simplemente la posibilidad, mediante el ejercicio de la diligencia debida, de identificar la ley que las partes o el propio legislador identifican como aplicable al régimen patrimonial (artículo 28, apartado 1 de ambos Reglamentos). La lex causae no puede vincular al tercero si no ha sido posible tener conocimiento de ella o siempre que la ley se haya aplicado con criterios excepcionales y en interés exclusivo de los cónyuges (artículo 26, apartado 3, penúltimo párrafo) ${ }^{44}$.

La mitigación del riesgo de inseguridad jurídica añade un valor adicional perseguido por el legislador europeo para lograr un mejor equilibrio entre la protección de los intereses de la pareja y los de los terceros relacionados. De hecho, cuando la lex causae rige el acuerdo entre una pareja y un tercero, o cuando un cónyuge o pareja reside en el mismo Estado que el tercero, la presunción de conocimiento está en vigor ${ }^{45}$. Debido al silencio de la ley, es posible debatir el alcance de la presunción que, en opinión de algún autor, se considera iuris et de iure, para minimizar el conflicto en un sistema normativo tan complejo, y favorecer la seguridad jurídica ${ }^{46}$. Merece atención la presunción de conocimiento introducida por el artículo 28 del Reglamento en relación con los bienes inmuebles: si de hecho, la lex causae coincide con la ley del Estado en el que se encuentran estos bienes, el tercero no tiene excusa en cuanto a su desconocimiento de la ley aplicable. Sobre la base del principio de unidad de la legislación aplicable, la aplicación de una ley que coincide con la ley del lugar en el que se encuentra el bien inmueble no puede ser una sorpresa: en tal caso, el tercero se beneficia de la coincidencia entre la lex causae y la lex registri, que no puede darse en otros casos.

El complejo y articulado sistema de interferencia entre la lex causae y la lex registri se especifica en el artículo 28, apartado 2, letra b). Como puede verse, en algunos Estados el régimen patrimonial de los cónyuges o las consecuencias patrimoniales de las parejas de hecho registradas se benefician de instrumentos de registro específicos o de sistemas de publicidad específicos. Si uno de los cónyuges o parejas de hecho ha cumplido con la obligación de registro exigida por la ley del Estado en el que se encuentra la propiedad, también en este caso la lex causae no puede sino coincidir con la lex registri. Si el registro se realiza siguiendo la ley del Estado cuya ley es aplicable a la relación entre el cónyuge o la pareja y el tercero, o la ley del Estado donde el cónyuge contratante y el tercero tienen su residencia habitual, el tercero no puede objetar la presunción legal de conocimiento de la ley aplicable.

El artículo 28 de ambos Reglamentos constituye un punto de referencia indispensable para entender cuál es la ley aplicable a la relación entre el cónyuge o la pareja y el

44 Según el artículo 26, "La aplicación de la ley de ese otro Estado no afectará negativamente a los derechos de terceros derivados de la ley aplicable en virtud del apartado 1, letra a)". El tercero no puede verse afectado por la lex causae si la autoridad judicial "con carácter excepcional y a petición de uno de los cónyuges", decide que la ley de un Estado distinto del Estado cuya ley es aplicable en virtud de la letra a) del apartado 1 regule el régimen económico matrimonial. Esta aplicación excepcional se produce cuando el solicitante demuestra que (a) los cónyuges han tenido su última residencia habitual común en ese otro Estado durante un período de tiempo significativamente más largo que en el Estado designado en virtud de la letra a) del apartado 1; y b) ambos cónyuges se han basado en la ley de ese otro Estado para organizar o planificar sus relaciones patrimoniales.

45 Véase el artículo 28 de los Reglamentos Gemelos.

46 Las presunciones también son relevantes en el ámbito de la sucesión. En cuanto a la presunción de buena fe del tercero, véase I. RIVA, Certificato successorio europeo. Tutele e vicende acquisitive, ESI, Nápoles 2017, pp. 161-166. 
tercero cuando la lex causae no es efectiva. La falta de concordancia entre la ley aplicable a las relaciones patrimoniales de la pareja y la ley aplicable al tercero se resuelve considerando la presencia o ausencia de bienes inmuebles. Si existe tal bien, el tercero se beneficia de la aplicación de la ley del Estado en el que se encuentra el bien, con la consiguiente aplicación de la lex registri. Si, por el contrario, no hay bienes inmuebles, la ley aplicable es la que se aplica a la transacción entre un cónyuge o una pareja y el tercero.

El artículo 28 del Reglamento supone una peculiaridad que merece ser analizada. Existe una discrepancia entre lo que se establece en materia de conocimientos jurídicos y lo que se establece en materia de ley aplicable al tercero en el caso de que no se pueda aplicar la lex causae. En el primer caso, el legislador sólo menciona los bienes inmuebles, y en el segundo, el legislador se refiere también a los "bienes o derechos registrados". La diferente redacción del texto puede superarse mediante una interpretación sistemática. Es evidente que cuando la titularidad de un bien o un derecho debe estar registrada para ser conocida e invocable, se da al tercero la posibilidad de conocer la existencia de derechos de propiedad sobre ese bien concreto o sobre la titularidad de ese derecho concreto.

\section{LEY APLICABLE A LAS RELACIONES PATRIMONIALES Y LOS EFECTOS FRENTE A TERCEROS}

El Reglamento determina que el régimen patrimonial de una pareja transfronteriza se rige por una ley previsible que regula todos los bienes, independientemente de su naturaleza o de los diferentes lugares en los que se encuentren ${ }^{47}$.

Sin embargo, esto también implica una comparación continua entre los diferentes sistemas normativos ${ }^{48}$. Los principales problemas a los que se enfrentan las parejas en la gestión del patrimonio familiar se refieren a la identificación de la titularidad de los bienes, la legitimidad de uno de los cónyuges para disponer de un bien perteneciente a la familia, las modalidades de registro de los bienes y la consiguiente invocabilidad frente a terceros.

Las consecuencias patrimoniales derivadas del régimen elegido por los cónyuges o socios reflejan sus derechos y obligaciones dentro de la organización familiar. Sin embargo, también son relevantes en lo que respecta a la publicidad necesaria para los efectos erga omnes de la propiedad de los bienes o de los derechos derivados de ellos ${ }^{49}$. Dependiendo de si el régimen patrimonial es de comunidad o de separación de bienes, también puede variar la condición de los terceros que ejercen derechos contra la pareja o contra uno solo de los miembros de la pareja basándose en la situación jurídica aparente.

47 Reglamento (UE) 2016/1103 del Consejo [2016] DO L183/1; Reglamento (UE) 2016/1104 del Consejo [2016] DO L183/30; L. RUGGERI, "I Regolamenti europei sui regimi patrimoniali e il loro impatto sui profili personali e patrimoniali delle coppie cross-border", en S. LANDINI (coord), EU Regulations 650/2012, 1103 and 1104/2016: Cross-border Families, International Successions, Mediation Issues and New Financial Assets, ESI, Nápoles 2020, pp. 118-130.

48 P. BRUNO, I regolamenti UE n. 1103/16 e 1104/16 sui regimi patrimoniali della famiglia: struttura, àmbito di applicazione, competenza giurisdizionale, riconoscimento ed esecuzione delle decisioni, en www.distretto.torino. giustizia.it.

49 P. BRUNO, I regolamenti europei sui regimi patrimoniali dei coniugi e delle unioni registrate, Giuffrè, Milano 2019, p. 185. 
Hay que tener en cuenta que las normas aplicables no sólo se refieren a la administración del régimen patrimonial, sino que también afectan a las situaciones de crédito o de deuda de cada cónyuge o pareja ${ }^{50}$. Por lo tanto, se concede especial importancia a la correcta identificación de la propiedad de los bienes adquiridos por la pareja y de su régimen patrimonial.

En algunos sistemas, principalmente de derecho anglosajón, el patrimonio de los cónyuges tiende a permanecer separado, sin perjuicio de una decisión judicial diferente ${ }^{51}$. En consecuencia, estos sistemas no incluyen por sí mismos el concepto de régimen matrimonial, de modo que la decisión sobre la asignación de los bienes o parte de las cuotas de propiedad se delega en el juez, incluso con independencia de la propiedad formal. El juez se basa en los criterios de razonabilidad y equidad ${ }^{52}$, pero también en la valoración de la contribución económica y personal que cada cónyuge ha hecho a la organización familiar. Los sistemas de derecho civil prevén en su mayoría la comunión de los bienes adquiridos por la pareja después del matrimonio ${ }^{53}$. Así, en el caso de que una pareja identifique la ley italiana como la ley aplicable a su régimen patrimonial, los bienes adquiridos individualmente por los miembros de la pareja constituirán bienes comunes si no se ha optado por el régimen patrimonial de separación. Esto es diferente en los demás Estados miembros. En Austria, por ejemplo, se prevé generalmente que la compra de bienes por parte de uno de los cónyuges siga siendo de su propiedad exclusiva o, alternativamente, si se compran conjuntamente, los bienes entran en copropiedad ordinaria. Por lo tanto, dependiendo de la ley aplicable, un acuerdo firmado por uno o ambos cónyuges o socios con un tercero determina diferentes efectos.

Como se indica en el considerando 52 del Reglamento sobre el régimen económico matrimonial, y en el considerando 51 del Reglamento sobre las consecuencias patrimoniales de las uniones registradas, la ley determinada como ley aplicable por la pareja debe incluir los efectos del régimen patrimonial de los cónyuges o socios en una relación jurídica entre un cónyuge y terceros. Sin embargo, los efectos de la ley elegida por los cónyuges o parejas de hecho sólo pueden invocarse contra un tercero si éste tiene conocimiento en virtud del artículo 27, apartado 1, letra f, de los Reglamentos gemelos. Por lo tanto, es necesario evaluar si los terceros tienen la posibilidad real o conocen con certeza

50 N. CIPRIANI, 'Rapporti patrimoniali tra coniugi, norme di conflitto e variabilità della legge applicabile' (2019) 1 Rassegna di diritto civile, 27, 29; M.J. CAZORLA GONZÁLEZ, 'Regímenes patrimoniales matrimoniales tras la disolución por divorcio: Connections and Variables that Determine the Applicable Law', en J. KRAMBERGER ŠKERL, L. RUGGERI, y F.G. VITERBO (coords), Case Studies and Best Practices Analysis to Enhance EU Family and Succession Law. Working Paper, en Quaderni degli Annali della facoltà giuridica dell'Università di Camerino 3, Università di Camerino, Camerino 2019, pp. 40-48, disponible en: https://afg.unicam.it/node/111 and also at https://www.euro-family.eu/news-126-case studies and best practices analysis to enhance eu family and succession_law_working_paper; L. RUGGERI, "Propiedad y parejas transfronterizas desde la perspectiva de la regulación europea" (2021) Actualidad Jurídica Iberoamericana, en prensa 15, pp. 252-274.

51 G. OBERTO, "La comunione coniugale nei suoi profili di diritto comparato, internazionale ed europeo" (2008), Il diritto di famiglia e delle persone 369. Véase también K. BOELE-WOELKI, F. FERRAND, C. GONZALES BEILFUSS, M. JÄNTERÄ-JAREBORG, N. LOWE, D. MARTINY y W. PINTENS, Principles of European Family Law Regarding Property Relations Between Spouses, Cambridge 2013, p. 11; G. OBERTO, "Il divorzio in Europa' (2021) 1 Famiglia e diritto 112.

52 G. PERLINGIERI, "Sul criterio di ragionevolezza”, en C. PERLINGIERI y L. RUGGERI (coords), L'incidenza della dottrina sulla giurisprudenza nel diritto dei contratti, ESI, Nápoles 2016, pp. 29-71.

53 Entre los Estados que prevén la comunión de bienes se encuentran los siguientes Bélgica, Francia, Italia, Luxemburgo, Portugal, España, Polonia, la República Eslovaca, la República Checa, Hungría, Rumanía y Bulgaria. 
los efectos o las consecuencias jurídicas que la ley aplicable afirma sobre el régimen patrimonial de la pareja y, por lo tanto, se basan en ello.

Si la elección de la ley de los cónyuges o de las parejas registradas puede modificarse en cualquier momento, también debe tenerse en cuenta la posición del tercero. Es necesario que el cambio de la ley elegida sólo pueda invocarse frente a terceros cuando se hayan respetado correctamente las formalidades requeridas para la inscripción en los registros correspondientes.

A este respecto, no obstante el artículo 27, letra f, de los Reglamentos, su artículo 28, apartado 1, prevé la inoponibilidad frente a terceros, en caso de litigio, de la ley aplicable al régimen patrimonial de los cónyuges o de los miembros de la pareja, a menos que el tercero conociera o, en el ejercicio de la diligencia debida, debiera haber conocido dicha 1 ley ${ }^{54}$. En tal caso, tal y como se determina en el apartado 3 del artículo 28, cuando la ley aplicable no puede ser invocada por un cónyuge frente a un tercero en virtud del apartado 1 del artículo 28, los efectos del régimen económico matrimonial con respecto al tercero se rigen por la ley del Estado aplicable a la transacción y, en los casos relativos a los bienes inmuebles, por la ley del lugar en el que se encuentran o en el que están registrados los bienes o derechos.

Por lo tanto, parece que es necesario adoptar normas armonizadas que puedan aclarar las modalidades en las que cualquier tercero puede tener conocimiento de la ley elegida por la pareja para regular el régimen patrimonial y así conocer las relaciones jurídicas que pretende establecer.

En lo que respecta a la relación jurídica, se presume la diligencia debida de las partes, que consiste en la carga de cumplir con la publicidad prevista por la ley aplicable con el fin de darla a conocer a los terceros, para evitar que se sometan inadvertidamente a normas distintas de las invocadas.

\section{LA INSCRIPCIÓN DE LOS DERECHOS REALES Y EL ÁMBITO DE APLICACIÓN DE LOS REGLAMENTOS GEMELOS}

De acuerdo con lo indicado en el considerando 27 de los Reglamentos gemelos, los requisitos relativos a la inscripción en un registro de un derecho sobre bienes muebles o inmuebles están excluidos del ámbito de aplicación de los Reglamentos. Por lo tanto, cada Estado miembro debe determinar las condiciones legales y los procedimientos de inscripción en sus propios registros de la propiedad, así como indicar las autoridades responsables de verificar los requisitos y la documentación necesaria.

El considerando 28 especifica además que los efectos de la inscripción de un derecho en un registro están excluidos del ámbito de aplicación de dichos Reglamentos gemelos. Estos reglamentos obligan a la ley del Estado miembro en el que se lleva el registro determinar si la inscripción tiene efectos declarativos o constitutivos. Por otra parte, el apartado 2 del artículo 1 de ambos Reglamentos excluye expresamente de su ámbito de

54 Sobre esta cuestión, véase A. ZANOBETTI, "Il regime patrimoniale della famiglia nel diritto internazionale privato", en F. ANELLI y M. SESTA (coords), Regime patrimoniale della famiglia, en Trattato di diritto di famiglia dirigido por P. ZATTI, vol. II. III, $2^{\text {a }}$ ed., Milán 2011, p. 43; A. CLERICI, “Art. 30”, en F. POCAR (coords) Commentario del nuovo diritto internazionale privato, Cedam, Padua 1996, p. 142. 
aplicación la "naturaleza de los derechos reales" (letra g), y "toda inscripción en un registro de los derechos sobre los bienes inmuebles o muebles, incluidos los requisitos legales para dicha inscripción, así como los efectos de la inscripción o de la falta de inscripción de dichos derechos en un registro" (letra h).

Es tarea del intérprete identificar en concreto el registro específico al que se refieren los Reglamentos. El estudio debe realizarse analizando la normativa interna, a falta de una definición de "registro" dentro de la normativa europea. Sobre la base de la lex registri será posible entender qué tipo de "registro" puede llevar a cabo la función de publicidad del régimen patrimonial de los cónyuges o parejas. Por ejemplo, si la lex registri es la ley italiana ${ }^{55}$, la publicidad se lleva a cabo en dos registros diferentes con funciones y efectos distintos: el Registro de la propiedad y el Registro civil ${ }^{56}$. Los bienes inmuebles deben inscribirse en el Registro de la propiedad ${ }^{57}$. El Registro Civil debe inscribir el matrimonio o la pareja de hecho registrada y el régimen patrimonial elegido por los cónyuges o socios. Por lo tanto, siempre es necesario consultar el Registro de la propiedad para conocer la titularidad de los bienes inmuebles y el Registro civil para saber qué régimen de propiedad han elegido los cónyuges o socios. El complejo sistema de publicidad italiano no está presente en otros países europeos que, por ejemplo, no incluyen un régimen de propiedad familiar registral específico y que ofrecen diferentes sistemas de publicidad de bienes inmuebles ${ }^{58}$.

Por lo tanto, para garantizar la seguridad del tráfico jurídico y el efecto erga omnes de la adquisición de un derecho sobre un bien mueble o inmueble, hay que remitirse al registro previsto en la legislación del Estado miembro correspondiente. Al mismo tiempo, debe tenerse en cuenta el régimen patrimonial elegido por la pareja, o los efectos patrimoniales en las uniones registradas. Así, en el caso de que una transacción haya sido realizado según la ley italiana, o el inmueble está situado en Italia, o una de las partes tiene residencia italiana, el registro del régimen patrimonial resultante de los trámites realizados sobre la base de la ley italiana puede invocarse contra cualquier tercero, incluso si la ley elegida por la pareja es la de un Estado miembro diferente o la de un tercer Estado. A este respecto, las letras a y b del apartado 2 del artículo 28 de los Reglamento gemelos establecen una presunción de conocimiento por parte del tercero ${ }^{59}$, cuando las partes han cumplido sus obligaciones de registro y publicidad.

Como ya se ha dicho, en la legislación italiana el Registro Civil da a conocer el régimen patrimonial elegido por los cónyuges o parejas, mientras que el Registro de la Propiedad da a conocer la inscripción de los bienes inmuebles. La ley italiana regula la

55 En la ley italiana, el sistema de registro de la propiedad o el régimen de propiedad de los cónyuges o parejas, es necesario tener en cuenta la pluralidad de los registros.

56 En Italia, el complejo sistema de divulgación de la propiedad inmobiliaria se realiza mediante la inscripción de los bienes inmuebles en el registro de la propiedad que lleva la "Agenzia delle Entrate". El registro es público y puede ser consultado por cualquier persona que lo solicite. Sobre esta cuestión, véase P. PERLINGIERI, Manuale di diritto civile, ESI, Nápoles, 2021, pp. 843-854.

57 Los matrimonios, las parejas de hecho registradas y el régimen patrimonial elegido por los cónyuges o parejas de hecho se inscribirán en el Registro Civil. La inscripción es obligatoria. El registro está presente en todos los municipios italianos.

58 Sobre este punto, véase el apartado 3 anterior.

59 E. CALÒ, arriba n. 1, 1097. En esta cuestión v. A. BONOMI y P. WANTELET, Le droit européen des relations patrimoniales de couple. Comentario a los Reglamentos (UE) 2016/1103 y 2016/1044, Bruylant, 2021, pp. 843-883. 
publicidad de los bienes inmuebles a través de dos sistemas diferentes ${ }^{60}$. El sistema de escrituras está en vigor en casi todo el territorio italiano, mientras que el sistema de títulos sigue funcionando en Friuli Venezia Giulia y en algunas otras provincias del norte, como Trento, Bolzano ${ }^{61}$. Una consecuencia de los Registros de la propiedad es la publicidad de los contratos constitutivos, traslativos y extintivos de la propiedad y otros derechos reales sobre bienes inmuebles. La divulgación declarativa tiene, por tanto, la función de atribuir un conocimiento jurídico a un hecho del que, en consecuencia, nadie puede alegar ignorancia.

La invocabilidad frente a terceros y a cualquiera que alegue la titularidad del inmueble se limita a los casos en los que se han cumplido debidamente las formalidades exigidas para la publicidad en dichos registros. Por ejemplo, la constitución del fondo patrimonial, si se trata de bienes inmuebles, también debe transcribirse (artículo 2647 del Código Civil), a pesar de que se requiere una apostilla en la escritura de matrimonio para que sea invocable frente a terceros acreedores. En términos más generales, el Registro de la propiedad constituye un sistema destinado a dar a conocer un caso concreto y a hacerlo invocable frente a cualquiera $y$, en consecuencia, también a atender las necesidades de protección de terceros.

Por lo que respecta al ordenamiento jurídico italiano, las normas previstas para el matrimonio son aplicables a las parejas de hecho registradas introducidas por la ley $\mathrm{n}^{\mathrm{o}}$ 76/2016, la llamada ley Cirinnà, que prevé una ampliación general de las disposiciones legislativas en materia de familia ${ }^{62}$.

\section{DECLARACIÓN DE BIENES Y EFECTOS RESPECTO A TERCEROS}

Con el fin de proporcionar una información lo más completa posible, el régimen patrimonial de la familia se menciona en el sistema de registro de los bienes en la "nota de transcripción" 63 . No obstante, sin que ello pueda constituir un medio de integración de la apostilla en el acta de matrimonio, sino sólo la publicidad declarativa prevista en el artículo 162 del Código Civil italiano. En este caso, de hecho, la publicidad de los regímenes patrimoniales asume la mera función de divulgación de información. Este tipo de divulgación ha sido objeto de examen por la jurisprudencia más reciente.

En el caso $n^{0} 376 / 2021^{64}$, R.C. solicitó a la administración concursal de su cónyuge, P.T., de quien se había separado legalmente, la propiedad exclusiva de un inmueble adquirido después de la separación, pero antes de la apertura del procedimiento concursal. La falta de mención del cambio de régimen patrimonial tras la separación en la

60 La inscripción en el registro de la propiedad italiano se distingue además en el sistema de escrituras y en el sistema de títulos.

61 El sistema de escritura denominado "trascrizione" tiene efectos declarativos. Otro sistema llamado "intavolazione" tiene efectos constitutivos. El sistema de Registros de la Propiedad se puede encontrar en https://e-justice.europa. eu/content land registers in member states-109-it.

62 Sobre las uniones civiles, véase G. PERLINGIERI, "Interferenze tra unione civile e matrimonio. Pluralismo familiare e unitarietà dei valori normativi' (2018) 1 Rassegna di diritto civile 102.

63 La "nota de transcripción", llamada "nota di trascrizione", es un documento que describe el bien que se va a registrar. Es un documento requerido para asistir a la grabación.

64 Cass. civ., 13 de enero de 2021, n. 376, en DeJure. 
nota de transcripción había impedido, de hecho, que los terceros tuvieran conocimiento de ello. Según la sentencia del Tribunal Supremo, los bienes adquiridos por uno de los cónyuges después de la separación legal no constituyen bienes gananciales. El hecho de la separación en sí mismo provoca la disolución de la comunidad legal. A efectos de que los efectos de la disolución de la comunidad derivados de la separación de los cónyuges sean invocables frente a terceros, la inscripción en el Registro de la propiedad debe considerarse necesaria y suficiente. Dicha inscripción debe corresponder al cambio de régimen de separación de bienes, con independencia de la apostilla del acta de separación en el certificado de matrimonio. Ello es necesario porque el sistema de escritura de divulgación es más accesible para su consulta, aunque sea oneroso, que el que figura en el certificado de matrimonio en el Registro Civil. Por lo tanto, el tribunal señala que, a pesar de la disolución de la comunidad jurídica entre los cónyuges, ésta no puede invocarse contra terceros de buena fe que se hayan basado en los resultados de la consulta al Registro de la propiedad, que no indicaban la separación de bienes resultante de la separación personal. Por ejemplo, la compra personal del inmueble no podría invocarse contra el tercero.

De este modo, el tribunal protege el contenido formal visible para los terceros a través del acceso a los Registros de la propiedad y no el contenido real del título de propiedad, que sí ha sido transcrito, pero es difícil de consultar.

De ello se desprende que, si bien hay que remitirse a la publicidad prevista en el Registro Civil para producir efectos erga omnes de los regímenes patrimoniales, también con el sistema de escrituras registrales se aumenta el grado de fiabilidad respecto a terceros y a la función social de la propiedad ${ }^{65}$.

Asimismo, al igual que ocurre con los registros para la inscripción del régimen patrimonial de los cónyuges o los efectos patrimoniales de las parejas de hecho registradas, los sistemas de transcripción de bienes inmuebles o de inscripción de hipotecas no están regulados de la misma manera en cada Estado miembro. Cada uno de ellos tiene un sistema de registro de bienes inmuebles y muebles inspirado en lógicas y mecanismos completamente diferentes.

A modo de ejemplo, según la legislación portuguesa, la inscripción de bienes inmuebles regulada en el Registro Predial tiene un efecto declarativo. Se puede invocar contra terceros si se ha ejecutado. En consecuencia, dicha inscripción representa una carga para el comprador. La inscripción en el Registro implica la presunción de que el derecho pertenece a la persona indicada como titular. Otro sistema diferente es el francés, donde existen varias oficinas de Registro de la propiedad, que no disponen de un mecanismo coordinado de recuperación de datos. Además, son difíciles de consultar, ya que los terceros no pueden acceder a ellas libremente.

La falta de homogeneidad de los sistemas de registro de la propiedad entre los Estados miembros parece exigir una mayor uniformidad de las normas. El objetivo es que el sistema de registro garantice efectivamente la invocabilidad del régimen patrimonial de las parejas transfronterizas y de la ley aplicable correspondiente frente a terceros.

65 G. PETRELLI, 'L'autententicità del titolo della transcrizione nell'evoluzione storica e nel diritto comparato' (2007) Rivista di diritto civile, 609. 


\section{ADAPTABILIDAD DE LOS DERECHOS REALES}

Por lo que se refiere al sistema de publicidad de los bienes de la pareja y de los regímenes patrimoniales, las normas introducidas por los Reglamentos gemelos no parecen ajustarse plenamente a la composición de las diferentes soluciones normativas de los distintos Estados miembros. Un mecanismo de publicidad armonizado podría facilitar la adquisición de conocimientos jurídicos sobre la propiedad de los bienes adquiridos por la pareja y los consiguientes efectos con respecto a terceros. La ley elegida para regular el régimen patrimonial también influye en las responsabilidades de las deudas de los cónyuges y parejas, y en consecuencia, también afectará a las relaciones con posibles terceros acreedores. De hecho, los Reglamentos gemelos determinan en su artículo 27, apartado c, la responsabilidad de un cónyuge o pareja por las obligaciones y deudas del otro cónyuge o pareja.

Sin embargo, el cambio de la ley aplicable al régimen patrimonial y a las consecuencias patrimoniales de un matrimonio o una pareja registrada puede dar lugar a la transferencia de los bienes de una categoría a otra. Si esto amplía o limita los derechos de uno o ambos cónyuges o parejas para disponer de los bienes, pueden producirse importantes efectos adversos para los terceros que habían confiado en dicho régimen ${ }^{66}$ si no se ha garantizado un grado adecuado de conocimiento del cambio realizado.

Si surge un conflicto entre la ley aplicable al régimen patrimonial de los socios o cónyuges y la del Estado en el que puede invocarse un derecho de un tercero, el artículo 29 del Reglamento permite la "adaptación de los derechos reales". Por lo tanto, aunque los derechos reales no están incluidos en el ámbito de aplicación de los Reglamentos gemelos, su considerando 24 determina que debe permitirse la creación o la transferencia de un derecho sobre bienes inmuebles o muebles, según lo previsto en la ley aplicable a los efectos patrimoniales de los cónyuges o al régimen matrimonial. Sin embargo, este derecho no debería afectar al número limitado de derechos reales conocidos en la legislación nacional de cada Estado miembro. Además, un Estado miembro no debería estar obligado a reconocer un derecho real relativo a bienes situados en ese Estado miembro si este derecho no se conoce en su sistema jurídico.

Una reciente decisión dictada por el TJUE resulta pertinente a este respecto ${ }^{67}$. En el asunto Kubicka (C-218/16), el ordenamiento jurídico alemán denegó a un ciudadano polaco residente en Alemania una solicitud de reconocimiento de los efectos materiales de un legado "por reivindicación", permitido por el Derecho polaco por el que el testador había optado de conformidad con el artículo 22, apartado 1, del Reglamento sobre sucesiones. La denegación se basó en el hecho de que el objeto del legado era un derecho real sobre un bien inmueble situado en Alemania, que no prevé el establecimiento de un legado con efectos materiales directos.

El TJUE subrayó que, por razones de seguridad jurídica, la ley elegida debe regir la sucesión en su conjunto, es decir, todos los bienes que forman parte de la herencia,

66 Véase L. RADEMACHER, arriba n. 15, pp. 7-18. De forma más general, véase W. PINTENS, "Matrimonial Property Law in Europe", en K. BOELE-WOELKI y J.M. SHERPE (coords), The Future of Family Property in Europe, Intersentia, Antwerp 2011, pp. 19-46; D. MARTINY, "European Family Law", en J. BASEDOW, K.J. HOPT y R. ZIMMERMANN (coords), The Max Planck Encyclopaedia of European Private Law I, Oxford 2012, p. 595.

67 Asunto C-218/16 Aleksandra Kubicka, ECLI: EU:C:2017:387. 
independientemente de la naturaleza de los bienes y de que éstos se encuentren en otro Estado miembro o en un tercer Estado. El TJUE también señaló que el legado "por reivindicación" previsto en el Derecho polaco, y el legado "por condena" previsto en el Derecho alemán, constituyen modalidades de transmisión de la propiedad de un bien y, como también destacó el Abogado General, un derecho real reconocido en los dos ordenamientos jurídicos en cuestión. El testamento del testador consistía esencialmente en transmitir un derecho real sobre un bien inmueble situado en territorio alemán mediante un legado "por reivindicación”. Por lo tanto, el TJUE consideró que el caso no se refería al método de transmisión de los derechos reales, sino únicamente al respeto del contenido de los derechos reales, por lo que debía reconocerse el derecho ${ }^{68}$.

El artículo 29 de los Reglamentos gemelos introduce la posibilidad de la adaptación de los derechos reales. Concretamente, si una persona invoca un derecho real sobre la base de la ley aplicable al régimen patrimonial, y la ley del Estado miembro en el que se invoca el derecho no prevé el mismo derecho, es posible adaptarlo al derecho equivalente más cercano según la ley de dicho Estado. Sin embargo, dicha adaptación debe realizarse teniendo en cuenta los objetivos y los intereses que persigue el derecho específico y sus efectos.

Por lo tanto, parece que para realizar un correcto análisis del derecho y llevar a cabo la consiguiente adaptación, debe realizarse una investigación no sólo en términos generales. Hay que examinar un caso concreto y perseguir una adecuada protección de los intereses que subyacen en ese proceso concreto ${ }^{69}$. Dicho proceso se inscribe en el principio más general de servir de la mejor manera posible a los intereses de los cónyuges o parejas, así como a los de terceros. Dicho examen tiene un valor positivo si el ejercicio de los derechos resulta adecuado para la realización de los intereses reales de las partes y para el cumplimiento de la ley con las disposiciones normativas aplicables ${ }^{70}$.

\section{OBSERVACIONES FINALES}

Aunque los Reglamentos gemelos han armonizado las normas que regulan el régimen económico matrimonial y los efectos patrimoniales de las parejas de hecho registradas, siguen existiendo muchas diferencias en el sistema de acceso al Registro de la propiedad y la publicidad de los bienes en los Estados miembros. Por lo tanto, habría sido útil prever una simplificación de los términos jurídicos en los Reglamentos gemelos y aplicar un sistema coordinado que facilitara el acceso a los diferentes registros de la propiedad en los Estados miembros. Esta disposición podría ciertamente incitar a los terceros a conocer el régimen patrimonial elegido por los cónyuges o parejas, y aumentar así el nivel de protección de los intereses de sus cónyuges, parejas y terceros. Así pues, parece necesario

68 Véase P. BRUNO, supra 19, pp. 220-221; D. DAMASCELLI, “Applicable Law, Jurisdiction, and Recognition of Decision in Matters Relating to Property Regimes of Spouses and Partners in European and Italian Private International Law" (2019) 1 Trusts \& Trustee, 6, 16; C. CONSOLO, "Profili processuali del Reg. UE 650/2012 sulle successioni transnazionali: il coordinamento tra le giurisdizioni' (2018) 1 Rivista di diritto civile 18.

69 Sobre este punto, cf. P. PERLINGIERI, Fonti e interpretazione, vol. II, Il diritto civile nella legalità costituzionale secondo il sistema italo-europeo delle fonti, $4^{\mathrm{a}}$ ed., ESI, Nápoles 2020, p. 379.

70 M. LIBERTINI, "Le nuove declinazioni del principio di effettività" (2018) 4 Europa e diritto privato, 1071. 
armonizar el sistema de registro de la propiedad y la publicidad de los bienes, y estos aspectos deberían ser objeto de una nueva acción normativa por parte de la Unión Europea.

En conclusión, si la uniformidad introducida por el artículo 21 de los Reglamentos gemelos delinea normas previsibles en aras de la certidumbre, debe seguir favoreciendose la provisión de modelos uniformes y funcionales de publicidad para la correcta identificación de los modelos patrimoniales adoptados y de los efectos consiguientes. 